Luiz Marques

Claudia Mattos

Mônica Zielinsky

Roberto Conduru

\title{
Existe uma arte brasileira? ${ }^{1}$
}

1. $\left(^{*}\right)$ Debate publicado originalmente em francês e português na revista Perspective, 2, 2013. Referência eletrônica: Luiz Marques, Roberto Conduru, Claudia Mattos et Mônica Zielinsky, "Existe-t-il un art brésilien ?», Perspective [On line], 2 | 2013. Texto em francês disponível em: URL : http:/l perspective.revues.org/3879 | Texto em português disponível originalmente em: URL: http://perspective.revues.org/5543.

\section{Como citar:}

MARQUES, Luiz; MATTOS, Claudia; ZIELINSKY, Mônica; CONDURU, Roberto. Existe uma arte brasileira? Porto Arte: Revista de Artes Visuais. Porto Alegre: PPGAV-UFRGS, v. 22, n. 36, p.1-20, jan.-jun. 2017. e-ISSN 2179-8001. DOI: http://dx.doi. org/10.22456/2179-8001.79600 


\section{DEBILIDADE E APORIAS DA HISTOGRAFIA ARTÍSTICA BRASILEIRA}

Luiz Marques

\section{Introdução}

Propor um panorama geral sobre a relação entre as artes figurativas no Brasil e os esforços de reflexão histórica que elas suscitam no país (e, mais raramente, no exterior) é um grande desafio. Em primeiro lugar, essa historiografia não foi até hoje objeto de um estudo completo ou de reflexões gerais. Ao nos aventurarmos nessa área, percebemos que o terreno e a paisagem não estão bem definidos. Não houve no Brasil historiadores da arte que estruturaram o cenário intelectual e definiram as suas linhas de força, como, por exemplo, Henri Focillon, na França, Roberto Longhi, na Itália, Julius von Schlosser, na Áustria, Erwin Panofsky e Edgar Wind, na Alemanha, Roger Fry, na Inglaterra, etc. Naturalmente, existem alguns nomes de referência, mas se trata em geral de escritores, ensaístas e jornalistas que eventualmente se dedicaram - para o bem ou para o mal - à história da arte. Além disso, até os anos 1980, a história da arte entendida como conhecimento metódico e como disciplina universitária associada a diplomas de graduação, mestrado e doutorado simplesmente não existia no Brasil. Ainda hoje, aliás, os cursos de história da arte são bem pouco numerosos.

Um segundo motivo a explicar a dificuldade de propor uma visão geral da historiografia artística brasileira associa-se ao fato de que os estudos sobre a arte no Brasil concentravam-se basicamente, até há pouco, em dois períodos históricos e em duas regiões do país: o barroco mineiro, com incursões isoladas no Rio de Janeiro, Bahia, Pernambuco e Paraíba (entenda-se por "barroco" a arte praticada durante o período colonial, grosso modo, entre o início do século XVIII e o início do século XIX) e o modernismo, termo utilizado aqui para designar a arte impregnada de nacionalismo produzida a partir da segunda década do século XX principalmente em São Paulo, Rio de Janeiro e, um pouco mais tarde, em Minas Gerais. Por esse motivo, momentos importantes da história das artes no Brasil - principalmente da arte produzida no século XIX - permaneceram quase esquecidos até os anos 1990. Enfim, e sobretudo, se a historiografia artística brasileira apresentou lacunas e careceu até os anos 
1980 de rigor universitário, foi também porque as artes figurativas produzidas no Brasil não mereceram, e em minha opinião com razão, a mesma atenção que outras artes, como a literatura e a música, cuja densidade atraiu a atenção mais metódica dos historiadores.

Essa terceira razão advém de um juízo de valor que deve ser explicitado e assumido. A esse respeito, duas precisões impõem-se. Primeiramente, como o foco do meu trabalho não é a história da arquitetura, nem a das artes decorativas ou a da chamada "arte contemporânea", limitarei minhas análises ao campo de estudos das artes figurativas stricto sensu. Em segundo lugar, é provável que a maioria dos colegas brasileiros provavelmente não compartilhe esse ponto de vista. É compreensível que quem quer que se dedique à história das artes figurativas no Brasil tenda a valorizar seu objeto de estudo e a lhe atribuir uma importância histórica e estética maior. Com exceção de casos específicos (Aleijadinho, algumas obras de Amoedo, Di desenhista nos anos '20, Portinari retratista, Goeldi...), a história da arte figurativa no Brasil, e especialmente a pintura, não parece, em meu entender, exibir uma relevância segura fora do âmbito da história local.

\section{Debilidade histórica das artes figurativas}

A debilidade da tradição figurativa e especialmente pictórica no Brasil é constitutiva. Sua matriz é lusitana. Tal como em Portugal, também na colônia a arte da figura no espaço sofre se comparada com outras artes, tais como a arquitetura, as artes decorativas, a literatura e a música. As oficinas mais exímias na arte da mobília e na de cinzelar e modelar o metal deixaram, tanto na metrópole quanto na colônia, monumentos dignos de figurar no mais seleto patrimônio artístico universal. Não há, contudo, nenhum pintor ou escultor português dos séculos XVI e XVII que figure, em qualquer sentido, ao lado de Camões ou de Antônio Vieira. Tampouco algum pintor da colônia equipara-se a Gregório de Matos, a poetas árcades luso-brasileiros, como Tomas Antônio Gonzaga (1744-1810) ou, de novo, a Antônio Vieira (por sua biografia e pelos destinatários de muitos de seus Sermões, Vieira é luso-brasileiro). Este déficit luso-brasileiro da representação da figura e do espaço figurativo em relação às demais artes prolonga-se nos séculos XIX e XX. Quem é o pintor, em Portugal ou no Brasil, que possa ser lembrado (com a única exceção, talvez, de Domingos Sequeira em seus melhores momentos) quando se evocam nomes como os de Alexandre Herculano, Camilo Castelo Branco, Eça de Queirós, Machado de Assis, Fernando Pessoa e Guimarães Rosa?²

Não esqueço aqui o conjunto admirável de esculturas que se atribui a Aleijadinho, mas este é, antes de mais nada, um arquiteto-escultor, educado
2. 0 balanço é igualmente adverso para a pintura luso-brasileira quando a comparação se faz com a música. Enquanto Vieira Lusitano (16991783) evolui à sombra de Trevisani, Carlos Seixas (1704-1742) é digno interlocutor de Domenico Scarlatti na Capela Real de Lisboa. Da mesma maneira, jamais um pintor brasileiro gozará do reconhecimento coletivo de Carlos Gomes, Villa-Lobos, Pixinguinha, Noel Rosa, Nazaré ou Antônio Carlos Jobim. 
3. De resto, nem em Portugal a escultura monumental pública tinha então uma tradição importante. A estátua equestre de D. José I, para o Terreiro do Paço, por Joaquim Machado de Castro, um discípulo de Alexandre Giusti, é a primeira estátua pública em bronze realizada naquele país. que foi por seu pai, um arquiteto português. Como escultor monumental, ele se ergue (com perdão do clichê) como uma torre isolada numa cultura coral do entalhe cujo desenvolvimento histórico foi drasticamente limitado pelos seguintes fatores:

e feira do Nordeste do Brasil, seu repertório iconográfico é pobre: o Cristo, a Sagrada Família, a Virgem em suas infinitas declinações, a Educação da Virgem, anjos, arcanjos, anjinhos e santos, não raro anônimos, dada a exiguidade de seus atributos;

com exceção novamente de Aleijadinho e de alguns raros casos, há nessa escultura pouco interesse pelo universo da expressão fisionômica;

a exuberância "barroca" dos drapeados compensaria a ausência do nu se o jogo dos panos não fosse, na média, de um convencionalismo "industrial". Não são raras, contudo, as exceções de bela musicalidade nas linhas, massas e ritmos dos panos;

enfim, trata-se de uma escultura sem grandes contrastes de poética, malgrado os esforços dos estudiosos e do mercado de arte brasileiros para criar "personalidades" e genealogias, agrupadas em imaginosas "escolas". Sem ser um estudioso dessa escultura, penso que alguns "não-Aleijadinhos" de alta qualidade artística que se encontram em

Na pintura colonial, esse déficit em relação à literatura e à música acusase de modo mais cruel. Sendo o espaço pictórico em perspectiva um construto muito intelectualizado, para cujo exercício é imprescindível um longo treino acadêmico, não surpreende a ausência de um Aleijadinho pintor. A pintura na colônia portuguesa manteve-se assim, sem exceção, num nível elementar e muito aquém não apenas, como dito, da proficiência das demais artes na colônia portuguesa, mas também da pintura das colônias hispano-americanas, como o comprovou mais uma vez a exposição proposta por Jonathan Brown em 2010-2011 em Madrid, intitulada, justamente, Pintura de los reinos. Identidades compartidas em el mundo hispânico, onde se percebe que não há praticamente fratura estética e sociológica entre a arte espanhola e a arte de suas colônias. Não se desenvolveu no Brasil dos séculos XVI ao XVIII uma estatuária monumental e uma pintura de um nível elevado por simples inexistência de demanda. A estatuária monumental pública pressupõe a necessidade de legitimação simbólica do poder político, necessidade inexistente na colônia portuguesa. 0 mesmo pode-se dizer da retratística e da grande decoração pictórica. Contrariamente à Nueva España no México e no Peru, ao Virreinato de Nueva Granada na Colômbia, à Nouvelle-France na Louisiane de Luís XIV e à New England do Nordeste dos Estados Unidos, o Brasil colônia, em sua esmagadora maioria composto de escravos e de mulatos bastardos como Aleijadinho, nunca foi e nunca se concebeu como um "Novo Portugal"3. 
No Brasil colônia, tudo o que a pintura pode oferecer aos historiadores são relíquias venerandas de uma prática artística que apenas excepcionalmente (Mestre Ataíde, talvez, se o afeto prevalecer sobre o juízo) elevou-se acima de um tosco artesanato serial. Nessas circunstâncias históricas, não se pode esperar dessa pintura que se mova no alto repertório, que seja culta em invenção, que saiba representar o espaço em perspectiva, o corpo nu segundo cânones clássicos ou outros, a complexidade dramática da narrativa visual e o calibrado comércio entre forma e expressão. Mas se poderia esperar que, tal como a arte popular afro-brasileira, indígena, "cabocla", etc, ela soubesse exprimir, com seus próprios meios, uma própria complexidade, algo de singularmente belo, ao invés de uma incontornável inépcia.

Naturalmente, como nossos tempos são os da global art e da caça ao eurocentrismo, muitos são os que acreditam que há uma própria inteligência na mera desinteligência dos códigos culturais do cristianismo e da cultura clássica. E engenham-se em descobri-la. São esforços generosos e, por vezes, brilhantes, mas temo que os resultados se devam mais à inteligência do historiador que à do fenômeno estudado.

\section{Debilidade histórica da historiografia artística}

Apenas a partir de meados do século XIX pode-se falar da existência de uma historiografia artística no Brasil. Em 1858, Rodrigo Ferreira Bretas escreveu uma biografia de Aleijadinho, na realidade, a única biografia artística do século. No mais, crônicas dos prêmios, das exposições e dos percalços da Academia Imperial, publicadas numa imprensa diversa e abundante, mas não raro efêmera, resumem a historiografia artística do século XIX na capital do Império. Seus autores conhecidos são em número de quatro: Félix-Émile Taunay, Manuel de Araújo Porto Alegre, Gonzaga Duque e Angelo Agostini, número irrisório, se comparado com a historiografia artística e a crítica de arte no México no mesmo período ${ }^{4}$. É claro que não há historiografia artística onde não há o que a suscite: uma classe média letrada e uma classe dominante visualmente educada, que reconheça no colecionismo uma estratégia de emulação e de afirmação cultural ${ }^{5}$. Mas esse raquitismo historiográfico deve-se também à acima discutida debilidade constitutiva da cultura figurativa brasileira. Pois as deficiências sociológicas acima apontadas não impediram enfrentamentos jornalísticos de bela têmpera retórica, como o que opõe Joaquim Nabuco (1849-1910) a José de Alencar (1829-1877) em torno da questão da escravidão. Não impediram tampouco uma crítica jornalística e uma produção historiográfica no campo da literatura. Basta lembrar da História da Literatura Brasileira publicada em 1882 (e na $5^{a}$ edição de 1953 em cinco volumes) por Sílvio Romero. Nada de
4. Cf. Ida Rodrigues Prampolini, La critica de arte en Mexico en el siglo XIX (Estudios y fuentes del arte en Mexico), 3 volumes, Universidad Nacional Autonoma de Mexico, 1997. 5. Em 1854, no discurso de posse na direção da Academia Imperial de Belas Artes, Manuel de Araújo Porto Alegre afirmava, conformado: "Não venho com desejos infundados, nem com a vaidade de ostentar exposições públicas em um país novo, no qual a riqueza e a aristocracia ainda não chamaram as belas artes para adornarem seus brasões e suas liberalidades". Cf. Luciano Migliaccio, Luciano. O Século XIX, N. Aguilar, Nelson (org). Mostra do Redescobrimento: Arte do Século XIX. São Paulo: Fundação Bienal de São Paulo, 2000, p.101. 
6. Cf. Joana Mello, Ricardo Severo: da arqueologia portuguesa à arquitetura brasileira. São Paulo, Annablume, FAPESP, 2007, com Prefácio de José Tavares Correia de Lira.

7. O termo, como se sabe, é de Mário de Andrade. Cf. Marcos Antonio de Moraes, "'Abrasileirar o Brasil'. Arte e literatura na epistolografia de Mário de Andrade". Caravelle, Toulouse, 80 , 2003, p.33-47. remotamente comparável pode-se afirmar de qualquer produção coeva da historiografia artística no Brasil.

\section{A historiografia nacional-modernista}

Nos outros países do Novo Mundo e nos países da Europa central, oriental, escandinava, balcânica e ibérica - periféricos em relação ao núcleo Itália, França, Países-Baixos e Inglaterra -, o modernismo e a historiografia do período prolongaram uma tradição romântica e nacionalista, de cunho oitocentista, que marcou seus materiais e seu ideário. De onde se poder designar o modernismo e a historiografia do período nesses países pelo termo nacional-modernista, algo substancialmente diverso do modernismo de matriz parisiense, isento de romantismo e pouco afeito à expressão de essências nacionais ou de psicologias profundas, ainda que à maneira de Worringer.

O Brasil não escapou ao típico. Mas há nele uma singularidade em relação aos demais nacional-modernismos. Diversamente dos países europeus "periféricos", ricos de tradição histórica; diversamente também da América hispânica, lastreada nas civilizações pré-colombianas, no Brasil o nacional-modernismo carecia de "material histórico": (1) não havia aqui quase nenhum registro documental e monumental de um passado multissecular; (2) dizimado, assimilado, refugiado em enclaves ou na selva amazônica, o índio era até meados do século XX uma abstração para o país urbano do litoral. Era ademais trademark do nativismo romântico do século XIX e fora tematicamente esgotado por José de Alencar, Carlos Gomes e por certos quadros de Pedro Américo e Amoedo. Em inícios do século $X X$, com exceção de algumas aquarelas parisienses de Vicente do Rego Monteiro, ele se reduzia ao trocadilho "Tupi or not Tupi" (1928) de Oswald de Andrade, excelente em tudo, e não menos por condensar o dilema hamletiano dos nacional-modernistas brasileiros; (3) enfim, a antiga cultura africana não fornecia um modelo viável num país visceralmente racista em relação aos negros, que tinha (e continua tendo) na escravidão o maior trauma de sua história e que buscava por todos os meios "embranquecer".

Premido por esse vácuo de referência histórica, ao nacional-modernismo brasileiro restava o estratagema de inventá-la ex nihilo. A certidão de nascimento dessa operação inverossímil é o impacto no Brasil da atuação tentacular de Ricardo Severo (1869-1940), um arquiteto português exilado no Brasil, conservador em sua prática arquitetônica e particularmente refratário ao modernismo europeu ${ }^{6}$. Figura erudita e influente nos círculos da elite paulistana, A atuação de Ricardo Severo promoverá uma transição sem tropeços de seu ideal de "reaportuguesamento" de Portugal ao ideal de "abrasileirização" do Brasil'. Lá, essa operação era uma reação ao abismo de um Portugal sem 
Império. No Brasil, ao menos em São Paulo, ela será em parte uma reação das elites locais à "invasão" de imigrantes, sobretudo italianos, cujos padrões superiores de cultura (inclusive política) e proficiência profissional ameaçavam sua hegemonia ideológica. Essa reação parece-me um ingrediente tácito, mas mais importante do que se costuma admitir, da mentalidade das elites patrícias que patrocinarão "seus" artistas na Semana de '22 e em outras jornadas. Da cruzada de Severo, o nacional-modernismo herdaria a ideia de que a Missão francesa de 1816 - ponto de partida de todo o esforço institucional de construção no Rio de Janeiro de uma cultura urbana moderna - havia desnaturado e recalcado as origens "barrocas" primordiais de nossa cultura.

Essa interpretação foi consagrada em 1955 por um intelectual de esquerda e crítico de arte sagaz das artes plásticas de seu tempo, Mário Pedrosa, que em sua Tese de 1955 afirmava: "os nobres davidianos vinham alterar o curso de nossa verdadeira tradição artística, que era barroca, via Lisboa"8. Em oposição a essa tese, tive mais de uma vez a oportunidade de lembrar que o barroco, fora de sua acepção estrita (isto é, a arte de Roma e de Nápoles nos anos 16201720 circa), presta-se particularmente mal a caracterizar o "temperamento de um povo" não-europeu, pois é uma arte europeia. $E$ tanto mais europeia o é em Portugal, onde, longe de emanar de um não sei quê de profundamente português, ela adentra o país por meio de encomendas régias e de corte a artistas italianos tais como Agostino Cornacchini, Camilo Rusconi e dezenas de outros. Sobretudo sob D. João V, o barroco português é uma arte de estrita observância romana. Portanto, a Missão Francesa, não significa, como pensa Pedrosa, o recalque de "nossa verdadeira tradição artística, que era barroca, via Lisboa" por uma cultura francesa estranha a essa "tradição". A Missão de 1816 é apenas o reflexo, no Brasil, da lenta passagem da hegemonia romana à hegemonia francesa nas Academias europeias, passagem que se inicia, se precisarmos de datas, com as encomendas vaticanas a Pierre Subleyras nos anos 1740 e se consuma com David.

Com raras exceções, que não podem ser consideradas neste espaço, a historiografia artística brasileira evolui até bem tarde no século XX no âmbito desse esquema triádico: (1) Barroco (origem); (2) Missão Francesa e seus desdobramentos (desvio); (3) Modernismo a partir das paisagens de Eliseu Visconti (reencontro). Não se atina então para o fato que a busca da "identidade" como programa é uma tautologia, pois não se pode desejar ser o que, inevitavelmente, já se é. De onde duas aporias: (1) reivindicar uma "identidade" é ipso facto a confissão de sua impossibilidade, já que tal reivindicação remete a um circuito fechado, um efeito de espelhos contrapostos, de strange loops autoreferenciais; (2) reivindicá-la é também uma contradição nos termos, já que supõe mimetizar o modelo europeu (já dotado de identidade). Essas aporias ganharam
8. Cf. Mario Pedrosa, "Da Missão francesa: seus obstáculos políticos" (1955), in O. Arantes, (org.) Mario Pedrosa: Acadêmicos e Modernos. Textos Escolhidos III. São Paulo, Edusp, 1998, p.83-84. 
9. Revista llustrada, Ano 4, 157, 16 de abril de 1879 (em rede).
10. Cf. Karoline Carula, As Conferências Populares da Glória $e$ as discussões do darwinismo na imprensa carioca (18731880). Dissertação de Mestrado, Universidade Estadual de Campinas, Unicamp, 2007. tanto maior pregnância e longevidade por emanarem da figura central do nacional-modernismo, Mario de Andrade, em cujo ensaio de 1928 sobre Aleijadinho a "mulatice muita" do escultor adquire valor de DNA da arte "brasileira".

\section{A sabedoria de Angelo Agostini}

Felizmente, a atual geração de historiadores da arte no Brasil interessa-se cada vez menos por esse gênero de retórica e por essa herança ideológica ao estudar a arte que se conserva no país e, sobretudo, aventura-se cada vez mais pela arte internacional. Percebe que na arte produzida no Brasil o adjetivo "brasileiro" não é uma categoria crítica, isto é, não aporta nada à sua inteligibilidade; percebe que essa inteligibilidade não emana de uma fantasmática instância autóctone, mas da rede de relações e condicionantes internacionais de que o Brasil e a arte que aqui se fez são o resultado. Pode hoje, enfim, entender a ironia de Angelo Agostini (1843-1910) em sua sátira do Salão de 1879 da Academia Imperial de Belas Artes, no qual se inaugurava candidamente uma sala intitulada "Escola Brasileira":

"Salão de 1879. Deixem-me aproveitar o fechamento da exposição, para fallar um pouco sizudamente (hum! hum!) sobre as pretensões do catálogo em que deparamos com o seguinte: 'Quadros, etc. etc. formando a ESCOLA BRASILEIRA'. (...) Mas tem graça a escola brasileira... A nossa Academia ouviu certamente falar em escola flamenga, italiana, e pensou ainda mais naturalmente que todo quadro pintado na Itália pertence à escola Italiana (...), assim como os quadros pintados no Brasil formam a escola brasileira. Isso é que é resolver a questão do nó górdio sem olhar nem à direita, nem à esquerda, como Alexandre. Mas eu, por mais que pense, que reflita, que estude os quadros da Pinacoteca, sempre que me falam em escola brasileira, lembro-me logo da escola da Glória, e fujo antes que caia em cima uma conferência".

Agostini exprime seu receio de que o tema da "Escola Brasileira" de pintura viesse a se tornar um entediante tema de preleção numa das Conferências da Glória que, desde 1873, tinham por objetivo a divulgação de temas científicos, filosóficos e literários ${ }^{10}$. Profético temor de incorrer na sorte de Sísifo de que só recentemente, enfim, nos liberamos.

\section{NOVOS HORIZONTES PARA A HISTÓRIA DA ARTE NO BRASIL}

Claudia Mattos

A história da arte como campo específico do saber no Brasil constituiu-se em primeiro lugar como herdeira direta da tradição historiográfica modernista. Como observa Luiz Marques, ela se concentrou nos três temas viscerais dessa historiografia: a arte barroca, com foco principal no barroco mineiro e na figura 
de Aleijadinho; a arte dita "acadêmica", centrada principalmente na análise da produção da Academia Imperial de Belas Artes do Rio de Janeiro; e, principalmente, o próprio modernismo. Esse último tornou-se de fato o campo articulador dos discursos hegemônicos sobre a história da arte no Brasil, ao menos até a década de 1980. A busca por uma identidade artística própria e a ideia de construção de uma arte de caráter especificamente nacional, características típicas do modernismo, repercutiram no campo da história da arte como um desejo de se concentrar na produção artística nacional e na tradição historiográfica local para construir uma história da arte essencialmente brasileira. É por esse motivo que as artes da Europa, incluindo as importantes coleções existentes no Brasil, como as do Museu de Arte de São Paulo ou do Museu Nacional de Belas Artes, permaneceram pouco estudadas durante um bom tempo, assim como todo o âmbito das artes de tradição não-europeia, como a arte africana, pré-colombiana, asiática, islâmica, entre outras. Devido a essa restrição histórica do campo aos temas mencionados, as significativas produções artísticas afro-brasileiras e ameríndias também foram esquecidas e, em larga medida, ainda são ignoradas por historiadores da arte no país, que constroem assim uma história da arte identificada com a história dos conquistadores europeus.

A falta de instituições capazes de oferecer uma formação específica na área de história da arte assim como a escassez de traduções de textos clássicos e recentes centrais à disciplina também dificultaram, por muito tempo, uma abordagem teoricamente complexa e atualizada do material estudado. $\mathrm{Na}$ verdade, durante várias décadas, o Brasil contou apenas com o curso de história da arte oferecido pelo Instituto de Belas Artes do Rio de Janeiro, inaugurado em 1961 e transferido para a Universidade do Estado do Rio de Janeiro em 1978. 0 primeiro curso de graduação em história da arte foi aberto em 2009 na Universidade Federal de São Paulo. No mesmo período, outros cursos similares foram criados em outras universidades. A partir dos anos 1990 acelerou-se o processo de tradução para o português de textos clássicos e mais recentes, fundamentais à formação de historiadores da arte. Foram então publicadas obras de autores como Erwin Panofsky, Giulio Carlo Argan, Michael Baxandall, Svetlana Alpers, Louis Marin, assim como de Hans Belting, Georges Didi-Hubermann, etc. Nesse contexto, também merece destaque o trabalho de tradução desenvolvido por algumas revistas acadêmicas, como Concinnitas, publicada pela Universidade do Estado do Rio de Janeiro, ou a Revista de História da Arte e Arqueologia da Universidade Estadual de Campinas, entre outras.

Com algumas raras exceções, a produção na área de história da arte no Brasil reduzia-se assim, até recentemente, a narrativas sobre trajetórias de artistas, com pouca ênfase na análise das obras. Raros trabalhos abordavam temas de relevância, como a história do colecionismo, as questões 
11. Nessa tradição da crítica de arte, devemos citar também Nelson Aguilar, Paulo Venâncio Filho, Rodrigo Naves, Lorenzo Mammí, Sonia Salzstein, entre outros. Cf. Mônica Zielinsky, La Critique d'art contemporaine au Brésil : parcours, enjeux et perspectives, Lille, 1999. 12. Ulpiano Bezerra de Meneses, "Fontes Visuais, Cultura Visual, História Visual. Balanço provisório, propostas cautelares", in Revista brasileira de história, 23/45, julho 2003. de patrimônio ou os aspectos da historia material da obra. Reflexões sobre o estatuto do objeto de arte ou sobre as teorias da imagem, por exemplo, estiveram igualmente em grande parte ausentes. Uma história da arte fundamentalmente documental - principalmente no caso da literatura sobre século XIX - e cronista, muitas vezes marcada pela falta de distanciamento teórico e crítico em relação ao objeto de estudo, configurava o tom predominante nesse campo até o fim da década de 1980.

Era frequentemente fora do âmbito específico da história da arte que se podiam encontrar interpretações mais vivas e ousadas sobre produção artística local, como nas reflexões dos próprios artistas, ou em campos afins, como a antropologia, a sociologia ou a filosofia. Nos anos 1970, em paralelo ao desenvolvimento da história da arte, figuras como Vilém Flusser e Haroldo de Campos tiveram importância central no desenvolvimento de uma reflexão teórica sobre arte no Brasil. Esses e outros autores estão na raiz de uma tradição semiótica da teoria da arte no Brasil que inclui intelectuais como Arlindo Machado e Lúcia Santaella - ambos ligados ao programa de pós-graduação em semiótica da Universidade Católica de São Paulo. Também no contexto intelectual paulista, podemos citar o trabalho da psicanalista e crítica de arte Suely Rolnik, que contribuiu para a difusão no Brasil das teorias de Gilles Deleuze e Félix Guattari. Além disso, desde os anos 1970, o campo da crítica de arte trouxe contribuições fundamentais às reflexões sobre arte, especialmente por meio da figura de Ronaldo Brito ${ }^{11}$. Nomes como Paulo Herkenhoff e Moacir dos Anjos, no campo da curadoria, e Sergio Miceli (responsável pela publicação em português de obras de Pierre Bourdieu pela editora da Universidade de São Paulo nos anos 1990), no da sociologia da arte, também ajudaram a enriquecer o debate artístico. Enfim, mais recentemente, o historiador e arqueólogo Ulpiano Bezerra de Meneses contribuiu de forma significativa para o desenvolvimento teórico da disciplina ao introduzir importantes discussões sobre teoria da imagem e dos estudos visuais no Brasil'12.

Até o final dos anos 1980, a dificuldade de circulação dos historiadores da arte brasileiros no exterior e uma falta de interesse da comunidade internacional pelo caso específico da América Latina e, em especial, do Brasil agravaram ainda mais a situação, produzindo um quadro de relativo isolamento do Brasil diante do contexto global. Vale ressaltar, no entanto, que a história da arte contemporânea era então uma exceção no país. Alimentados pelo vivo debate com os artistas, historiadores da arte como Ronaldo Brito, no Rio de Janeiro, ou Walter Zanini, em São Paulo, produziram uma historiografia artística de relevância. Do ponto de vista da articulação institucional do campo, é importante citar ainda a presença do Comité Brasileiro de História da Arte, fundado em 1972 e filiado ao Comité Internacional de História da Arte, como tênue canal 
de comunicação com a comunidade internacional e como espaço de encontro e articulação profissional dos historiadores da arte no país.

A situação geral da história da arte no Brasil começou a mudar rapidamente a partir da década de 1980, quando foram abertos diversos cursos de pós-graduação na área e muitos profissionais buscaram qualificar-se fora do país, ainda que esse fenômeno infelizmente tenha permanecido demasiadamente restrito às regiões Sudeste e Sul. Aos poucos, uma nova geração com experiência e contatos internacionais passou a atuar no Brasil, expandindo as fronteiras temáticas e entendendo o campo da história da arte em sintonia com os rumos internacionais da disciplina. Essa mudança coincidiu com o desenvolvimento de uma atitude crítica em relação aos caminhos da própria história da arte no mundo, o que incluiu uma abertura para a incorporação de novos objetos no horizonte dos estudiosos, assim como uma revisão dos princípios teórico-metodológicos que fundamentavam o conhecimento do historiador da arte até então. A retomada de Aby Warbug e Alois Riegl, por exemplo, como modelos para uma história da arte crítica ajudou a reduzir as distâncias entre "alta" e "baixa" arte, expandiu o campo de expertise do historiador da arte para o contexto mais amplo da cultura visual e ofereceu uma referência mais dinâmica em relação à questão da circulação da cultura material (e imaterial) através do globo, desconstruindo assim uma história da arte ainda marcada pelo conceito de escolas locais. O lugar da fala dos protagonistas de uma história da arte tradicional também começou a ser revisto por meio de abordagens pós-coloniais.

Ao observar o novo quadro que se configurou para a história da arte no Brasil a partir dos anos 1980 e 1990, notamos mudanças significativas, tanto no que diz respeito aos objetos e temas abordados, quanto à qualidade da reflexão teórico-metodológica. Do ponto de vista da abrangência temática, podemos dizer que, aos poucos, os limites impostos historicamente à disciplina foram sendo transpassados. Os trabalhos sobre a produção do século XIX, por exemplo, - como os desenvolvidos por Jorge Coli, Alexandre Eulálio, Luciano Migliaccio, Rafael Cardoso, Ana Paula Simioni Cavalcanti, Maraliz Christo ${ }^{13}$, entre outros - mostraram uma tendência salutar a não mais se restringir à criação dos gêneros tradicionais da pintura e escultura reconhecidos pela academia, e de sua relação com a tradição europeia, mas ao contrário, a procurar entender a produção do século XIX sob uma ótica mais dinâmica, ressaltando a importância da fotografia, da imprensa ilustrada, da participação de artistas acadêmicos em expedições científicas, ou mesmo de seus envolvimentos diretos com outras instituições relevantes, como o Instituto Histórico e Geográfico Brasileiro. Com isso ressaltou-se, por exemplo, a importância da fotografia para a representação do Estado durante o Segundo Império. O foco em questões de gênero e as tentativas de compreender a vasta produção afro-brasileira em relação ao
13. Sobre esse assunto, cf. os trabalhos de Luciano Migliaccio no catálogo da Mostra do redescobrimento, 2000, citação no 6; Rafael Cardoso, o design brasileiro antes do design: aspectos da história gráfica, 1870-1960, São Paulo, 2005; Rafael Cardoso, A arte brasileira em 25 quadros, Rio de Janeiro, 2008; Ana Paula Cavalcanti Simioni, Profissão artista: pintoras e escultoras acadêmicas no Brasil, São Paulo, 2008. Cf. também os seguintes trabalhos acadêmicos: Claudio José Alves, Natureza e Cultura nas Ilustrações da Comissão de Exploração Científica (1859-1861), tese de doutorado, Universidade Estadual de Campinas, 2012; Maria Antônia Couto da Silva, Um Monumento ao Brasil: considerações acerca da recepção do livro Brasil Pitoresco, de Victor Frond em Charles Ribeyrolles (1859-1861), tese de doutorado, Universidade Estadual de Campinas, 2011; Rosângela de Jesus Silva, O Brasil de Angelo Agostini: Política e sociedade nas imagens de um artista (1864-1910), tese de doutorado, Universidade Estadual de Campinas, 2010. 
14. Sobre esse processo de revisão teórico-metodológica do barroco no Brasil, cf. os trabalhos de Jens Baumgarten e André Tavares Pereira (Universidade Federal de São Paulo): Jens Baumgarten, "Staging Baroque Worship in Brazil", in David Morgan E., Religion and Material Culture: The Matter of Belief, Londres, 2010, 1 v., p.173-192; Jens Baumgarten, “O Corpo, a Alma e o Amor: Esculturas do Brasil Colonial entre o Performático e o Religioso", in Desígnio, 3, 2005, p.27-36; André Tavares Pereira, "Zeferino da costa e as pinturas da candelária”, in Thule, Dinámica de la Religiosidad en América Latina, 2003.

15. Cf. Renata Maria de Almeida Martins, Tintas da terra tintas do reino: arquitetura e arte nas Missões Jesuíticas do Grão-Pará (1653-1759), tese de doutorado, Universidade de São Paulo, 2009; André Tavares Pereira, A constituição do programa iconográfico das irmandades de clérigos seculares no Brasil e em Portugal no século XVIII: estudos de caso, tese de doutorado, Universidade Estadual de Campinas, 2006.

16. Um dos primeiros a questionar a história do modernismo foi Carlos Zílio com a publicação de seu livro A querela do Brasil: a questão da identidade da arte brasileira, a obra de Tarsila, Di Cavalcanti e Portinari, 1922-1945 (Rio de Janiero, 1982). Em 1995, Tadeu Chiarelli publicou sua tese de doutorado Um Jeca nos Vernissages (São Paulo, 1995) que propunha uma importante revisão do papel de Monteiro Lobato na história da crítica de arte no Brasil. Cf. também: Sergio Miceli, Nacional Estrangeiro, São Paulo, 2003; Letícia Squeff, "Paris sob 0 olho selvagem: Quelques Visages de Paris, de Vicente do Rego Monteiro", in Alex Miyoshi E., O selvagem e o civilizado nas artes, fotografia e literatura do Brasil, Campinas, 2010, 1 v., p.57-81. Sobre a tentativa de compreender o modernismo em seu contexto latino-americano, cf. Maria Amélia Bulhões, Maria Lúcia Kern EE., Territorialidade e práticas artísticas na América Latina, Porto Alegre, 2002; Jorge Schwartz, Vanguardas Latino-Americanas, São Paulo, 2010. campo da arte acrescentaram riqueza e complexidade aos estudos realizados entre as décadas de 1980 e 1990 . O mesmo pode ser dito com relação ao barroco. Da historiográfica tradicional, centrada no caso mineiro e em figuras excepcionais, como Aleijadinho e Ataíde, passou-se a uma abordagem muito mais dinâmica, focada na circulação da cultura material, não só no Brasil, mas no âmbito global do império português. Tentativas de compreender o sentido e a função dos diversos programas religiosos e o seu caráter performático, em um ambiente marcado pelo encontro de diversas tradições visuais e por contextos políticos específicos, diluíram os discursos essencialistas e nacionalistas, preocupados como o "autêntico" e o "original" na cultura barroca local14. Estudos importantes sobre o período colonial em diversas regiões do país, como Belém do Pará e capitais do Nordeste, ajudaram a construir um novo quadro para os estudos sobre o período colonial no Brasil ${ }^{15}$. Por último, uma revisão sistemática da noção do modernismo como "marco zero" da arte contemporânea no país, assim como uma tentativa de compreender suas manifestações em associação com as vanguardas latino-americanas e através do mundo, ajudou a situar o modernismo em um contexto internacional e a posicioná-lo de forma mais adequada no processo de desenvolvimento das artes no país ${ }^{16}$. Mais recentemente, em grande parte devido ao desenvolvimento de programas de graduação e pós-graduação em história da arte que incluem arte não-europeia em seus currículos, como é o caso dos programas de graduação da Universidade Federal de São Paulo e da Universidade do Estado do Rio de Janeiro, assim como da recém-inaugurada linha de arte não-europeia do programa de pós-graduação da Universidade Estadual de Campinas, a produção artística de raiz não-europeia - africana, ameríndia, asiática, islâmica, entre outras - passou também a ser objeto de análise de historiadores da arte no Brasil, algo que ganha especial relevância diante da multiplicidade cultural do país. A grande lição que tiramos de tudo isso é que a aparente debilidade da arte e da história da arte no Brasil depende diretamente da lente que usamos para avaliá-la. Renovados os óculos, a realidade adquire complexidade e riqueza.

Do meu ponto de vista, portanto, a principal diferença entre a historiografia da arte anterior aos anos 1980 e a produção atual encontra-se no âmbito da qualidade da reflexão teórico-metodológica. Em sintonia com os desenvolvimentos da história da arte no mundo, aos poucos construíram-se modelos muito mais dinâmicos e complexos para a compreensão da produção artística e da historiografia da arte do Brasil. A profissionalização do campo impulsionou a integração do Brasil à comunidade internacional de historiadores da arte. A consequência foi um aumento significativo do número de traduções de textoschave para os atuais debates teóricos da disciplina, assim como o aumento de publicações sobre o Brasil em revistas internacionais. O crescimento da 
colaboração internacional também foi significativo. Nesse ponto, faz-se necessário mencionar o apoio oferecido nestes últimos anos pelo instituto Getty de Los Angeles, que tem fomentado o desenvolvimento do campo por meio de projetos como "Connecting Art Histories" - três projetos dessa natureza foram aprovados recentemente para a história da arte no Brasil - ou por meio de convites a historiadores da arte brasileiros para integrar o programa de pesquisadores visitantes junto ao Getty Research Institute. Hoje esses profissionais estão mais presentes do que nunca nos principais fóruns internacionais da disciplina. É fascinante observar o resultado desse encontro, também para os rumos de uma nova história da arte global.

\section{HISTORIOGRAFIA DA ARTE BRASILEIRA EM BUSCA DE SEU LUGAR}

Mônica Zielinsky

$\mathrm{Na}$ parte final de seu texto, Luiz Marques afirma que "na arte produzida no Brasil o adjetivo 'brasileiro' não é uma categoria crítica [...] essa inteligibilidade não emana de uma fantasmática instância autóctone, mas da rede de relações e condicionantes internacionais de que o Brasil e a arte que aqui se faz são os resultados". Essa constatação, de suma importância para as reflexões sobre a existência de uma arte brasileira e de sua historiografia, é apresentada por Marques a partir de alguns exemplos da arte colonial brasileira e da historiografia desse período.

Entre as várias ponderações emergentes do texto de Marques, uma se evidencia: ele afirma considerar, antes de tudo, o "fenômeno artístico, antes de tratar [...] da historiografia artística". No entanto, em sua abordagem da arte e especialmente da arte do período colonial, percebe-se uma ótica depreciativa em relação à produção artística no país, sugerindo, por meio de juízos quase sempre de cunho formalista, sua pouca qualidade plástica. Ele assinala a debilidade da tradição figurativa, o repertório formal pobre de Aleijadinho, o pouco interesse pelo universo da expressão fisionômica; situa a pintura da colônia portuguesa em um nível elementar, afirmando que ela carece de longo treino acadêmico e apresenta características de um tosco artesanato serial; nega a existência de uma escultura em escala monumental entre os séculos XVI e XIX, alegando a ausência de encomendas e, dessa forma, de uma legitimação simbólica e expressiva da parte do poder político na colônia portuguesa.

Uma historiografia do período já estaria, em seu ponto de vista, comprometida na medida em que não daria conta de uma produção artística tão débil e inconsistente, incapaz de oferecer, por essa debilidade, um material valioso para o desenvolvimento de uma historiografia mais adensada. 0 autor também menciona a arte popular afro-brasileira, indígena ou "cabocla" - que poderia 
17. Rodrigo Naves, doutor em filosofia e bolsista do Centre of Brazilian Studies do St. Antony's College, em Oxford, é crítico e historiador da arte reconhecido no Brasil. Foi editor do suplemento Folhetim do jornal Folha de São Paulo e da revista Novos Estudos do Centro Brasileiro de Análise e Planejamento (CEBRAP); também participou das publicações $A$ parte do fogo e Beijo e é responsável pelo projeto editorial da coleção Espaços da arte brasileira da editora Cosac Naify. É autor de El Greco: um mundo turvo (São Paulo, 1985), Amílcar de Castro (São Paulo, 1991), A forma difícil: ensaios sobre arte brasileira (São Paulo, 1996) et do romance 0 filantropo (São Paulo, 1998).

18. Naves, 1996 , citação no 23 , p.10.

19. Naves, 1996, citação no 23 , p.10.

20. Naves, 1996, citação no 23, p.12.

21. Rodrigo Naves, "[...] Um azar histórico. Desencontros entre moderno e contemporâneo na arte brasileira", in Novos Estudos Cebrap, 64, novembro de 2002, p.18. revelar-se como algo "singularmente belo" - como um possível caminho para a criação de problemáticas próprias. Ele a julga, também aqui, "de uma incontornável inépcia", apesar de reconhecer que existem estudos de qualidade na abordagem dessas práticas por parte de alguns historiadores brasileiros.

Todas essas observações estimulam algumas conclusões sobre esse ensaio: nele, a arte desenvolvida no país é considerada precária; não se percebe no texto de Marques uma predisposição para compreendê-la em maior profundidade. Não há menção a dados documentais nem a metodologias de análise condizentes com os processos de construção das histórias locais e que contemplem suas implicações mais amplas e comparativas com outras culturas. 0 ensaio também não considera os nexos sociais e políticos, nem o papel das migrações e as diferenças presentes na anatomia dessa arte. Na verdade, ele não aposta efetivamente no fenômeno artístico citado. Diante de uma produção historiográfica apresentada como débil e praticamente inexistente, é preciso questionar o tipo de historiografia que, de uma maneira diferente, poderia um dia vir a se constituir.

Vale rever as posições sobre esse assunto assumidas por alguns estudiosos brasileiros, começando por Rodrigo Naves ${ }^{17}$. Em A forma difícil: ensaios sobre arte brasileira, o crítico e historiador da arte considera a produção das artes plásticas brasileiras irregular e esparsa, "um material incerto" em relação à boa parte das reputações públicas de sua tradição ${ }^{18}$. Mas o mais importante é a menção ao fato de que a condição da arte no país jamais justificaria a falta de conhecimentos e o despreparo da área para a constituição de um meio historiográfico mais rigoroso e enriquecedor ${ }^{19}$, que pudesse aprofundar sua natureza e reconhecer suas particularidades históricas e antropológicas. Essa posição se distingue da reflexão de Marques, para quem não há historiografia artística "simplesmente porque não há o que a suscite".

Diante dessas controvérsias, Naves se propõe a buscar nas próprias obras de arte as razões sobre a sua pouca repercussão no exterior e se interessa em compreender o que ocorre na produção brasileira ao incorporar as mudanças modernas e ao assumir, nessa perspectiva, "um viés todo particular"20. Detém-se na especificidade dos trabalhos, apontando "a sua forma difícil" em relação aos modelos da arte moderna internacional, de natureza ambiciosa e amparada por uma densa tradição criativa. Salienta a morosidade perceptiva da arte desenvolvida no Brasil e a timidez de suas configurações, cores e imagens, que ele considera distantes das inovações e das rupturas da arte dos circuitos dominantes. Reconhece os contornos diferenciados das artes plásticas no país em relação aos da arte dos centros hegemônicos, afirmando que as produções brasileiras extraem das dificuldades que Ihes são inerentes - principalmente da sua dificuldade de formalização - uma força 
estética admirável ${ }^{21}$. Esse seu texto de 1996 apresenta uma ambivalência: por um lado, não chega a aprofundar as conexões entre os fluxos culturais e históricos da arte no país e suas articulações com a estrutura multicultural da sociedade contemporânea, nem as questões a respeito dos contingentes institucionais que nela se tramam. Por outro, é um estudo que tenta fugir à perspectiva homogeneizante da cultura global e busca as diferenças e as particularidades dessa arte em sua concepção e em suas práticas. Ele a considera uma recriação local com seus contornos próprios e ressalta a importância em "compreender melhor a arte que produzimos, a partir de seus valores intrínsecos e de sua historicidade [...]"22, fatos que Marques aparentemente parece esquecer ao apresentar a arte colonial desenvolvida no Brasil. Ao refletir não apenas baseado em diferenças, mas principalmente a partir das diferenças ${ }^{23}$, Naves contribui de forma valiosa para a reflexão aqui proposta.

Um segundo caminho se apresenta às discussões motivadas pelo ensaio de Luiz Marques, propiciando um terreno fértil para a ampliação da questão historiográfica no Brasil. Esse enfoque é desenvolvido pelo pesquisador francês (residente no Brasil) Stéphane Huchet ${ }^{24}$, o qual, ao contrário de Luiz Marques, considera a arte brasileira dotada de uma qualidade irrefutável, pois assegura que "quem não vive no Brasil não tem ideia do vigor da criação artística no país" ${ }^{25}$. Com foco na arte contemporânea brasileira, ele contrapõe, por meio de uma análise minuciosa, a qualidade incontestável da arte produzida no país a uma historiografia da arte inconsistente e que ainda não conquistou o seu lugar - fato igualmente apresentado por Naves. Para o estudioso francês, a historiografia brasileira carece de uma formação teórica mais aprofundada e pertinente que lhe possibilite embates meta-históricos e conceituais. Faltam-Ihe igualmente métodos atualizados, assim como um incremento das pesquisas de campo. Huchet aponta problemas de inconsistência institucional, tanto na área acadêmica (que oferece poucos cursos de bacharelado em história da arte), quanto no meio editorial (edição, tradução e difusão de publicações) - fatos que atrasam o fortalecimento da repercussão local e internacional das produções artísticas e acadêmicas brasileiras. A difusão desses trabalhos não alcança as condições citadas no texto de Marques, que menciona a necessidade de se projetar a arte que aqui se fez e que aqui se faz em uma rede de relações internacionais na qual ela possa ser mais reconhecida e difundida. No entanto, Huchet apresenta o ganho que as exposições internacionais têm trazido à visibilidade dessa arte e menciona alguns exemplos, como Les Magiciens de la terre, apresentada em 1989 em Paris ${ }^{26}$. Com foco primordial na descentralização cultural, essa mostra permitiu colocar em xeque as práticas artísticas situadas às margens sociais e geopolíticas ${ }^{27}$. 0 autor menciona o impulso dado por essa exposição
22. Naves, 2002, citação no 27, p.18. 23. Gerardo Mosquera e Jean Fisher destacam a importância dessa ótica na introdução da obra editada por eles: Over Here : Internationa Perspectives on Art and Culture, New York/Cambridge (MA), 2004.

24. Stéphane Huchet, "Presença da arte brasileira: história e visibilidade internacional", in Concinnitas: revista do Instituto de Artes da UERJ, 1/12, 9 , julho de 2008, p.48-65 [ed. orig. "Présence de l'art brésilien : histoire et visibilité internationale", in Revue art histoire : Cahiers du Centre Pierre Francastel, número "Histoire et historiographie. L'art du second XXe siècle", 5-6, outono de 2007, p.229246].

25. Huchet, 2008, citação no 30, p.49.

26. Les Magiciens de la terre, JeanHubert Martin E., (cat. expo., Paris, Centre Georges-Pompidou, 1989), Paris, 1989

27. Vale consultar a minuciosa entrevista de Benjamin Buchloh com Jean-Hubert Martin sobre os princípios norteadores dessa exposição: "Entretien Benjamin H. D. Buchloh et Jean-Hubert Martin", in Les Cahiers du MNAM, 28, verão 1989, p.5-14. Recentemente reproduzida in Sophie Orlando, Catherine Grenier EE., Art et mondialisation : décentrements, anthologie de textes de 1950 à nos jours, Paris, 2013. 
28. Huchet, 2008, citação no 30 , p.64.

29. Amílcar Cabral se refere à dominação imperialista. Amílcar Cabral, "O papel da cultura na luta pela independência", in Obras escolhidas de Amilcar Cabral, Lisboa, 1, p.234-235 ; Gerardo Mosquera, "The Marco Pólo syndrome: some problems around art and eurocentrism", in Zoya Kocur, Simon Leung E., Theory in Contemporary Art Since 1985, Malden (MA), 2005, p. 219.

30. Cf. Hal Foster, "O artista como etnógrafo", in Arte e Ensaios, 12/12, 2005, p.138.

31. Expressão empregada por Walter Mignolo, in Local Histories/ Global Designs: Coloniality, Subaltern Knowledges and Border Thinking, Princeton, 2000. Cf. a análise dessa obra feita por Serge Gruzinski, in Annales: histoire, sciences sociales, 2002, 57/1, p.234-235, e Walter Mignolo, "Géopolitique de la sensibilité et du savoir. (Dé)colonialité, pensée frontalière et désobéissance épistémologique", in Mouvements, $\mathrm{n}^{\circ}$ 72, dezembro de 2012, disponível em: www.mouvements.info/Geopolitiquede-la-sensibilite-et.html (Acesso em: 15 de novembro de 2013). ao desenvolvimento de várias outras e, sob esse prisma, afirma que "a arte brasileira passa a ser do mundo, plenamente. As instituições internacionais finalmente a compreenderam"28.

Ainda que tenha exposto a importância dessa inserção da arte produzida no Brasil na dinâmica artística mundial - ideia também delineada na parte final do texto de Marques -, Huchet não chega a considerar o tipo de investimento político e simbólico que essas articulações implicariam - discussão que também mereceria uma uma cuidadosa reflexão. Sobre esse aspecto, a historiografia da arte brasileira certamente teria muito a dizer. É lacunar ainda, nos estudos de história da arte no país, a presença de pesquisas que esclareçam a importância das articulações dessa arte com a pluralidade de outros campos sociais, políticos, econômicos e antropológicos -, todos imprescindíveis para a compreensão dos fenômenos artísticos brasileiros no contexto de uma história da arte global e cosmopolita que, com frequência, omite as histórias e as aspirações locais de onde estes fenômenos provêm. Ao apresentar em seu ensaio a produção artística da colônia portuguesa que considera tão depauperada, Luiz Marques poderia ter feito a sua história emergir no presente. Isso porque essa arte solicita uma visão periférica, voltada aos seus aspectos híbridos, relacionais e apropriativos, que não foram mencionados por ele. Como afirma Amílcar Cabral, lembrado por Gerardo Mosquera, a análise dessa produção talvez pudesse erigir novos mundos para o nosso mundo atual ${ }^{29}$.

Cabe a essa historiografia da arte brasileira gerar as necessárias transformações epistemológicas ${ }^{30}$ e suscitar novos desafios disciplinares acadêmicos por meio de modelos relacionais de diversidade adaptados à história dessa cultura e dessa arte. Ela poderia, assim, permitir o florescimento de um pensamento construído a partir de seus limites, um pensamento de borda e que provém do "habitar a borda"31. Essa posição não é defendida nem por Marques, tampouco por Naves ou por Huchet. Ao conceber o adjetivo "brasileiro" como emanado de uma rede de relações e condicionantes internacionais, Luiz Marques não particulariza a posição e as características próprias do Brasil nesse contexto. Naves, em sua busca pelo viés particular da arte brasileira, não reflete sobre o lugar que essa particularidade poderia assumir em uma historiografia contemporânea em tempos de globalização. Huchet, ao contrário, omite o particular, ao refletir sobre a inserção artística brasileira nas dinâmicas globais da arte, sem mencionar as negociações e as rearticulações que poderiam ser estimuladas pela integração da arte brasileira nesse sistema mundial.

Para que a arte brasileira seja reconhecida no contexto geopolítico mundial, é preciso que ela circule de forma efetiva na rede global da arte contemporânea - mas isso não é suficiente. A constituição de uma historiografia crítica e atualizada que acompanhe, discuta e amplie essa produção e os seus processos 
de inserção é imprescindível à própria natureza da chamada arte "brasileira". Como uma "identidade em ação" ${ }^{2}$, essa historiografia, em seu modo específico de fazer a contemporaneidade, exige que os marcos locais sejam ultrapassados e que uma nova cartografia da arte no país seja criada. Em uma perspectiva jamais monolítica, mas por meio dos referidos modelos de alteridade, essa historiografia deve articular as confluências e as influências dessa arte em meio às culturas que a constituem e que com ela se associam. Longe de ser marcada pela fragilidade, a arte desenvolvida no Brasil deve se identificar com uma historiografia em processo, a que marcará suas diferenças e será sem dúvida politicamente inovadora, ao reconhecer assim o seu devido lugar na cultura mundial.

\section{A HISTÓRIA DA ARTE NO BRASIL, "DE CÁ PARA LÁ"}

Roberto Conduru

Apesar do tom laudatório de seus textos publicados em 1835 e 1841, que deram início à reflexão crítica sobre a arte no Brasil, Manuel de Araújo Porto -Alegre não deixou de indicar as limitações da produção artística da antiga colônia portuguesa e mesmo da produção anterior à presença europeia na América $^{33}$. Hoje parece difícil encontrar quem defenda a existência de uma forte tradição historiográfica da arte no Brasil. Um indício recente da persistência desse juízo negativo é a interpretação feita por Rodrigo Naves da "dificuldade de forma" que "perpassa boa parte da melhor arte brasileira"34. É comum o sentimento de inferioridade na comparação com os domínios da música e das letras no país, assim como com outras tradições historiográficas. Em vez de ser um elemento mobilizador, a pequena quantidade de obras, em sua maioria não extensas e pouco ambiciosas (mas não por isso menos importantes e até, por vezes, grandiosas), assim como a falta de sistematicidade - em suma, a ausência de uma tradição - é um travo para quem se dedica a refletir sobre arte no Brasil e que precisa enfrentar o peso do silêncio e dos mitos gerados pela descontinuidade crítica em um ambiente profissional rarefeito.

Os fatores que recentemente têm dinamizado a historiografia da arte no Brasil também não são totalmente positivos, pois não chegam a romper completamente certos impasses históricos, reforçando assim antigos problemas ou constituindo novos empecilhos. A proliferação de cursos de graduação ${ }^{35}$ e de pós-graduação ${ }^{36}$ em história da arte, especialmente na última década, não consegue reverter a tradicional concentração de recursos pessoais, físicos e financeiros do país, que decresce a partir da região Sudeste em direção às regiões Sul, Centro, Nordeste e Norte; ou seja, trata-se de um fenômeno que está em compasso com a desigualdade social brasileira.
32. Cf. Gerardo Mosquera, "Notas sobre globalización, arte y diferencia cultural", in Zonas Silenciosas, Amsterdam, 2001.

33. Manuel de Araújo Porto-Alegre "Résumé de l'histoire de la littérature, des sciences et des arts au Brésil", in Jean-Baptiste Debret, Voyage pittoresque et historique au Brésil, 3 v., Paris, 1839, p.84-87 [ed. orig. : Journal de l'Institut Historique, 1, 1835]; Manuel de Araújo Porto-Alegre, "Memória sobre a antiga escola fluminense de pintura", in Revista do Instituto Histórico e Geográfico Brasileiro, 3, 1841, p.547-557.

34. Naves, 1996 , citação no 23 , p.21.

35. Sobre cursos de graduação em história da arte, cf. Carlos Terra E., Arquivos da Escola de Belas Artes, Rio de Janeiro, 2010, p.41-90.

36. Sobre cursos de pós-graduação em história da arte, cf. Almerinda Lopes, "Reflexões sobre a história da arte e 0 historiador de arte no Brasil", in Vis, Brasília, 2006, p.33-50. 
37. Mário Pedrosa, "A Bienal de cá para lá", in Otília Arantes E., Mário Pedrosa: política das artes, São Paulo, (1970) 1995, p.217284 [ed. orig. : Ferreira Gullar E., Arte brasileira, hoje, Rio de Janeiro, 1973, p.1-64].

38. Ao menos desde a exposição Brazil Builds: architecture new and old, 1652-1942, realizada no Museu de Arte Moderna de Nova York em 1943.

39. Hélio Oiticica, "Esquema geral da nova objetividade" [1967], in Luciano Figueiredo et al. E., Hélio Oiticica: aspiro ao grande labirinto, Rio de Janeiro, 1986, p.98.
Embora o crescente trânsito internacional de pesquisadores radicados no Brasil esteja promovendo maior intercâmbio profissional, essa dinâmica ainda é refreada por uma menor mobilidade se comparada a outros contextos. A ampliação do interesse de pesquisadores estrangeiros pela arte brasileira ainda não teve a sua correspondente reflexão incorporada ao debate no país. A maior interação entre esses grupos pode gerar atritos e consonâncias, configurando um diferencial no campo historiográfico, interna e externamente.

Apesar de ser notório o salto quantitativo e qualitativo das publicações sobre arte nos últimos 20 anos - algo que têm ampliado a condição pública da arte no Brasil -, a preponderância do modelo de coffee table book e as pequenas tiragens limitam o pensamento crítico e a sua difusão. A concentração de monografias sobre as trajetórias e as realizações de indivíduos, sobretudo de artistas, também é dominante, em um processo de diferenciação que rompe com as visões essencialistas e homogêneas (embora não esteja de todo desvinculado do culto à personalidade, tão caro ao mercado de arte). É importante destacar aqui os estudos sobre artistas, entre os quais se sobressaem coletâneas de textos de críticos e historiadores dos últimos 50 anos, que, ao constituir um corpus, viabilizam e demandam maior reflexividade na historiografia da arte no Brasil.

Tomando como mote o título de um texto de Mário Pedrosa, "A Bienal de cá para lá"37, pode-se pensar a historiografia da arte no Brasil a partir da situação atual da arte e de sua reflexão crítica, em vez de tomar os valores pretéritos europeus como parâmetros de juízo. Em vez de operar com concepções de arte e de história geográfica e historicamente fixadas, parece mais produtivo partir de um aqui e agora móveis, mutantes: "cá" não é necessariamente o Brasil, mas a situação social de ideias, coisas e sujeitos, mesmo em trânsito; "lá" também é a princípio vago, temporal e espacialmente extensível, podendo alcançar a pré-história - as sociedades existentes no território sul-americano antes da presença europeia -, a África porosa, plural e ativa, e ir além, o que pode acarretar em uma ampla alteridade. A posição contemporânea pode ajudar a ver e pensar a multipolaridade do mundo, não apenas agora, mas, sobretudo, no passado.

Talvez a arte produzida no Brasil nos últimos 70 anos $^{38}$, bem acolhida por instituições e agentes artísticos estrangeiros, possa ativar outras visões, sejam retrospectos ou proposições historiográficas. "Da adversidade vivemos": a sentença de Hélio Oiticica, tantas vezes citada, pode ajudar nesse contexto ${ }^{39}$. Para uma historiografia que precisa lidar com deficiências, as realizações artísticas nutridas na precariedade podem servir como estímulos. Podem ser citados, entre outros, a incorporação do abjeto e da alteridade proposta por Lygia Clark em Baba antropofágica, de 1973; o modo como Frans Krajcberg reverte a 
violência humana ao potencializar destroços calcinados da natureza; a capacidade de reinvenção de si e do mundo de Arthur Bispo do Rosário ao manipular artefatos supostamente insignificantes e dejetos.

Uma outra formulação de Oiticica também pode nos servir de alento: tratase de, a partir da posição "subterrânea" do Brasil, "erguer-se como algo específico ainda em formação", insistindo na "posição crítica universal permanente e o experimental"40. Para se pensar a historiografia da arte produzida na complexa experiência (pós-)colonial, pode ser necessário garimpar aqui e ali autores, obras, trechos e até fragmentos, não exclusivamente publicados no Brasil, que iluminem outros caminhos. No conjunto um tanto errático de história, crítica, crônica e memória, entre outros gêneros, que esse garimpo pode produzir, talvez haja algo comparável à obra de Manuel Mousinho, o crítico português atuante no Brasil inventado por Ronaldo Brito em 1983 e sobre o qual ele escreveu: "dispersas, perdidas quase, em suas inúmeras notas, vamos encontrar idéias, comentários e indicações acerca das artes plásticas que merecem ser consideradas, no mínimo, provocantes, e, algumas delas, geniais até"41.

A história da arte esboçada por Porto-Alegre é nacionalista, monárquica, clerical, antilusitana, francófila, linear e evolucionista, mas, apesar de tudo, ele chegou a pensar em potenciais aberturas. Embora ele entendesse o processo histórico da arte no Brasil, na passagem da condição de colônia à de nação, como reflexo da mudança da centralidade artística da Itália à França, em suas considerações, o Egito é uma referência, assim como o Oriente. É possível assim ver como a ideia de uma história da arte mais inclusiva, ainda que centrada na Europa, germinava mesmo nas margens do sistema ocidental. Essa amplitude também foi delineada nas categorias artísticas e nas origens dos artistas citados. Em seu texto de 1835, ele menciona realizações nas áreas de arquitetura escultura, pintura, cerâmica, numismática e joalheria ${ }^{42}$, constituindo assim um precedente local para uma prática historiográfica que, coerentemente com a não restrição da arte a um tipo de objeto, amplia seu campo de ação, dando valor a vários tipos de obras e textos. Ao apresentar artistas que "honram a terra em que nasceram", Porto-Alegre inclui um alemão, um filho de italianos e um ex-escravo afro-descendente entre os oito artistas constitutivos da escola fluminense (originária do Rio de Janeiro) de pintura ${ }^{43}$, delineando assim uma "brasilidade" irrestrita ao Brasil.

Nos escritos do arquiteto e urbanista Lúcio Costa, encontra-se de modo claro a defesa do nacionalismo e o entendimento do modernismo como movimento que reativou a tradição genuína da "arte brasileira", estancou a desarticulação anteriormente introduzida pelo sistema acadêmico e se conectou com a arte produzida no período em que o Brasil era uma colônia portuguesa. Essa leitura culmina na eleição de Aleijadinho e do arquiteto Oscar Niemeyer,
40. Hélio Oiticica, "Brasil diarreia" [1970], in Ronaldo Brito et al., O Moderno e o contemporâneo, Rio de Janeiro, 1980, p.27.

41. Ronaldo Brito, "Manue Mousinho, um polemista secreto" [1983], in Sueli de Lima E., Ronaldo Brito: experiência crítica, São Paulo, 2005, p.103

42. Porto-Alegre, 1839 , citação no 39

43. Porto-Alegre, 1841, citação no 39. 
44. Lúcio Costa, Registro de uma Vivência, São Paulo, 1995, p.199. 45. Cidade criada em 1713 na região Sudeste do Brasil. 46. Costa, citação no 50, p.282. emparelhados, como expressões máximas do "gênio nacional"44. Por outro lado, ele cita Paris, o paisagismo inglês, a relação entre arquitetura e território na China, estradas e viadutos nos arredores de Nova York, além de Diamantina ${ }^{45}$, como os "'ingredientes'" da concepção urbanística de Brasília, a capital inventada para o futuro da nação ${ }^{46}$. Seria possível encontrar em seu trabalho, assim como em outras obra artísticas e historiográficas, elementos que ajudem a transformar e a reverter o universalismo simultaneamente submisso ao nacionalismo e ao eurocentrismo? Uma reflexão crítica do processo de mundialização cultural poderia contribuir ao desenvolvimento de práticas historiográficas livres de centros e margens, avessas ao nacionalismo e a seu oposto, sem deixarem de estar situadas socialmente?

\section{Luiz Marques}

Ex-curador do Museu de Arte de São Paulo. Professor de história da arte na Universidade Estadual de Campinas. Coordenador da Coleção editorial A Palavra da Arte, da Editora da Unicamp.

\section{Claudia Mattos}

Professora de História da Arte na Universidade Estadual de Campinas e Presidente do Comité Brasileiro da História da Arte. Sua pesquisa se concentra na arte brasileira dos séculos XIX e XX, bem como na historiografia e na teoria do arte.

\section{Mônica Zielinsky}

Mônica Zielinsky Professora de História, Teoria e Crítica da Arte na Universidade Federal do Rio Grande do Sul, no Programa de Pós-graduação em Artes Visuais, em Porto Alegre. Coordenou o catálogo raisonné do trabalho do artista Iberê Camargo e dirigiu, entre outras, a publicação de Fronteiras: arte, crítica e outros ensaios (2003).

\section{Roberto Conduru}

Professor de História e Teoria da Arte na Universidade do Estado do Rio de Janeiro. É autor da Arte Afro-Brasileira (2007) e Coleção Gilberto Chateaubriand, 19201950 (2011). 